\title{
HUBUNGAN PENGETAHUAN DAN KEMANDIRIAN KELUARGA TERHADAP KEJADIAN STUNTING DI WILAYAH KERJA PUSKESMAS SABULAKOA KABUPATEN KONAWE SELATAN
}

\section{THE RELATIONSHIP OF FAMILY KNOWLEDGE AND INDEPENDENCE TO THE EVENT OF STUNTING IN THE WORK AREA OF THE SABULAKOA HEALTH CENTER SOUTH KONAWE DISTRICT}

\begin{abstract}
Yovitas Sakona $^{1}$ Univesitas Indonesia Timur Makassar, Indonesia $^{1}$ email: yuvitasakona01@.gmail. com

IJI Publication p-ISSN: 2774-1907 e-ISSN: 2774-1915 Vol. 2, No. 1, pp. 26-30 Nopember 2021

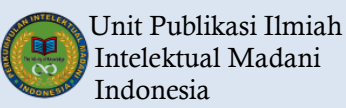

\section{PENDAHULUAN}

Perkembangan anak pasti jadi atensi khusus orang tua agar anak selalu terpenuhi asupan gizi dan nutrisinya. Yang menjadi permasalahan penting kesehatan anak diumur emas adalah kekurangan gizi kronik pada masa perkembangan serta pertumbuhan sampai terjadinya stunting (Elis \& Mustari, 2020). Stunting yaitu anak balita yang kekurangan asupan gii sehingga terjadi kegagalan dalam pertumbuhan menjadikan anak pendek dari usiannya (Muslih, 2018). Gangguan perkembangan pada otak, fisik dan metabolisme serta gangguan kepintaran biasanya dialami oleh anak yang stunting.

Stunting ialah keadaan dimana anak mengalami gangguan pertumbuhan ditandai dengan usia tidak sesuai dengan tinggi atau Panjang badan anak. Stunting adalah keadaan yang serius yang dialami anak yang asupan gizinya tidak tercukupi dalam jangka waktu lama. Stunting secra global berada pada nilai $15-17 \%$ dari seluruh kematian anak. Meskipun sehat, prestasi anak stunting di sekolah akan yang mengakibatkan kurang produktif di masa yang akan datang (Samantha \& Almalik, 2019). Menurut WHO 
stunting menjadi salah satu permasalahan di dunia dimana pada tahun 2017 terdapat $(22,2 \%) \quad 150,8$ juta balita mengalami stunting di dunia. Berdasarkan data report tahun 20052017 situasi balita pendek di Indonesia yakni sebesar 36,4\% balita mengalami stunting yang menempatkan Indinesia di peringkat ketiga dengan proporsi tertinggi di Asia Tenggara (Kementerian Kesehatan RI, 2018).

Tahun 2018 hasil Riskesdas di Provinsi Sulawesi Tenggara tentang status gizi nilai tertinggi, gizi baik sebesar 78,8\%, gizi kurang $13,2 \%$, gizi buruk $6,3 \%$, gizi lebih $1,7 \%$. Dari identifikasi tersebut didapatkan $26,2 \%$ bayi dan balita menderita stunting (Riskesdas, 2018) Berdasarkan data yang ada di Kabupaten Konawe Selatan Tahun 2017 sebanyak 478 balita BGM dan 17 kasus gizi buruk. Dan didaptkan $27 \%$ bayi balita mengalami stunting di Kabupaten Konawe Selatan (Profil Puskesmas Sabulakoa, 2020). Masalah gizi adalah permasalahan yang terjadi berdampak pada status gizi juga kondisi kesehatan sesorang serta perkembangan yang meliputi fungsi keceerdasan anak, keberhasilan di bidan akademik dan juga kesempatan mendapatkan kehidupan yang layak di masa depan (Sanjiwani et al., 2020). Pengetahuan keluarga menjadi faktor penyebab tidak langsung karena kurangnya pengetahuan keluarga tentang stunting sehingga mengakibat pemberian makanan dan pola asuh anak stunting kurang baik (Syahbandini \& et al, 2018).

Faktor yang mendukung terjadinya stunting adalah sikap orang tua seperti pemberian ASI yang tidak tepat (Sari \& Evy, 2018) dan konsumsi makanan di rumah dipengaruhi oleh kebiasaan orang tua yaitu ibu dalam memenuhi gizi anaknya. Penyakit infeksi juga menjadi salah satu penyebab stunting yang menjadi faktor langsung yang mana ditimbulkan dari tingkat kebersihan diri dan lingkungan yang tidak bersih, turunnya berat badan pada anak karena penyakit infeksi yang diderita (Kemenkes RI, 2018) Apabila keadaan tersebut berlangsung terus menerus yang tidak ditangani dengan asupan yang baik dalam penyembuhan akan berdampak terjadinya stunting (Heryanto \& Martha, 2019).

Dibidang gizi dan farmasi wajib dibiasakan makan dengan gizi yang seimbang, mengkonsumsi tabelt tambah darak pada saat hamil, penerapan ASI Eksklusif, mengkonsumsi garam yang beryodium dan lain-lain (Samantha \& Almalik, 2019) Bidan mempunyai peran penting dalam pencegahan dan penatalaksanaan stunting dimana bidan berperan dalam memberikan pelayanan kesehatan bekerjasama lintas sektor (perangkat desa). PIS-PK merupakan program yang menjadi salah satu kegiatan luar gedung yang menjadi wadah dalam pencegahan dan penanganan stunting.

\section{METODE}

Dalam penelitian ini digunakan desain analitik dengan rancangan cross sectional yaitu untuk menilai ada hubungan antara Pengetahuan dan Kemandirian Keluarga terhadap Kejadian Stunting di wilayah Kerja Puskesmas Sabulakoa Kabupaten Konawe Selatan. Populasi pada penelitian ini yaitu semua Ibu yang mempunyai anak yang usia 2-5 tahun yang ada di wilayah kerja Puskesmas Sabulakoa Kabupaten Konawe Selatan periode Januari-Agustus 2021 berjumlah 298 orang. Sampel pada penelitian sebanyak 74 orang.sumber data pada penelitian ini terdiri atas 2 yaitu Data Primer yang didapatkan dengan melakukan wawancara kepada responden mengunakan kuisiioner. Data yang dikumpulkan meliputi pengetahuan dan kemandirian keluarga terhadap kejadian stunting. Data Sekunder didapatkan dari data Puskesmas Sabulakoa Kabupaten Konawe Selatan ang berupa cakupan pelayanan kesehatan pada adan stunting. Instrumen penelitian dipergunakan 
yaitu kuisioner yang dibagikan pada ibu yang memiliki anak stunting. Teknik Analisis Data menggunakan software Statistical Product and Service Solution (SPSS) versi 22 yaitu Analisis Univariat Analisisi yang digunakan untuk mendeskripsikan karakteristik responden atau variable dalam penelitiian baik sendiri atau kelompok. (Siswanto \& Suyanto, 2018). Analisis Bivariat Analisis yang digunakan untuk menguji hipotesis hubungan antara dua variabel dengan uji statistik disesuaikan dengan skala data yang ada. Uji statistik yang digunakan adalah uji Chi-Square, tingkat signifikan data uji chi squere adalah $5 \%$ ( $\alpha$ $=0,05$ ), apabila hasil uji didapatkan $p<\alpha=0,05$ makaterdapat hubungan yang signifikan antara variabel bebas dengan variabel terikat.

\section{HASIL DAN DISKUSI}

Berdasarkan data tabel Hubungan Kemandirian Keluarga terhadap Kejadian Stunting di Wilayah Kerja Puskesmas Sabulakoa Kabupaten Konawe Selatan menunjukkan jumlah anak yang mengalami stunting pada Kemandirian Keluarga yang kurang yaitu 41 orang $(93,2 \%)$ lebih banyak dibandingkan dengan balita yang mengalami stunting dengan Kemandirian Keluarga yang baik yaitu tidak ada (100\%). Berdasarkan uji Chi-square hubungan Kemandirian Keluarga terhadap kejadian stunting menunjukkan nilai 0,000 . Dimana $p$-value $0,000<0,05$ sehingga dapat ditarik kesimpulan bahwa terdapat hubungan antara Kemandirian Keluarga dengan kejadian stunting di wilayah kerja Puskesmas Sabulakoa Kabupaten Konawe Selatan.

Berdasarkan hasil peneliitian menunjukkan bahwa dari 74 sampel tingkat pengetahuan keluarga yang kurang sebanyak 37 orang $(88,1 \%)$ mengalami stunting yang mana lebih tinggi dibandingkan keluarga dengan pengetahuan yang baik sebanyak 4 orang $(12,5 \%)$ yang mengalami stunting. Tingkat pengetahuan keluarga yang kurang pada anak yang normal sebanyak 5 orang
$(11,9 \%)$ dan tingkat pengetahuan keluarga yang baik pada anak yang normal sebanyak 28 orang $(87,5 \%)$.

Hasil uji Chi-square terdapat hubungan Pengetahuan terhadap kejadian stunting dengan nilai signifikan 0,000 . Karena $p$-value $0,000<0,05$ sehingga bisa disimpulkan bahwa ada hubungan yang signifikans antar pengetahuan dengan kejadian stunting di wilayah kerja Puskesmas Sabulakoa Kabupaten Konawe Selatan. (Danna, 2019) menyatakan semakin tinggi pendidikan sesorang maka smakin mudah bagi keluarga dalam menyerap informasi sehingga tingkat pendidikan dapat mempengaruhi tingkah laku sesorang dalam memperbaiki kondisi kesehatanya. Tetapi tingkat pengetahuan keluarga yang baik belum menjamin mempunyai anak dengan status gizi yang baik pula. Keluarga terutama ibu dengan pengetahuan baik diharapkan nantinya merealisasikan pengetahuannya dalam kehidupan sehari-hari. Penelitian ini juga sejalan dengan (Hasnawati et al., 2021) tentang "Hubungan Pengetahuan Ibu dengan Kejadian Stunting pada Balita Usia 12-59 Bulan" bahwa terdapat hubungan pengetahuan ibu dengan kejadian stunting pada balita usia 12-59 bulan di wilayah kerja Puskesmas Lawawoi Kabupaten Sidrap. Peneliti berpendapat bahwa kurangya pengetahuan orang tua anak stunting bukan karena tingkat pendidikan mereka yang rendah atau kurangnya informasi kesehatan dari tenaga kesehatan Puskesmas Sabulakoa melainkan karena keluarga kurang memahami dan kurang memperhatikan informasi yang disampaikan karena mereka menganggap hal tersebut tidak penting.

Berdasarkan hasil penelitian menunjukkan balita yang mengalami stunting kebanyakan karena Kemandirian Keluarga yang kurang yaitu 41 orang $(93,2 \%)$ balita yang mengalami stunting dengan Kemandirian Keluarga yang baik tidak ada (100\%). Kemandirian Keluarga yang kurang 
pada anak yang normal sebanyak 3 orang $(6,6 \%)$.

Hasil uji Chi-square hubungan Kemandirian Keluarga terhadap kejadian stunting menunjukkan nilai signifikans 0,000. Karena $\rho$-value $0,000<0,05$ maka dapat ditarik kesimpulan terdapat hubungan yang signifikans antar Kemandirian Keluarga terhadap kejadian stunting di wilayah kerja Puskesmas Sabulakoa Kabupaten Konawe Selatan. (Puspita, 2017) menyatakan kemandirian adalah kemampuan indiviidu dalam mengatur diri sendiri dan tak bergantung pada orang lain. Kemandirian meliputi perilaku yang inisiatif, dapat menyelesaikan hambatan ataupun masalah, memiliki rasa percaya dirii tanpa dibantu orang lain. Penelitian ini sejalan dengan (Danna, 2019) yang menyatakan bahwa adanya hubungan kemandirian keluarga dengan kejadian stunting di Puskesmas Bulak Banteng Surabaya. Peneliti berpendapat bahwa pekerjaan orang tua balita yang stunting juga berpengaruh terhadap kemandirian keluarga dimana kedua orang tua lebih fokus untuk bekerja sehingga kurang memperhatikan tumbuh kembang.

Tabel 1

Distribusi Frekuensi Pengetahuan Keluarga di Wilayah Kerja Puskesmas Sabulakoa Kabupaten Konawe Selatan

\begin{tabular}{llcc}
\hline No & Pengetahuan & Frekuensi & Presentase (\%) \\
\hline $\mathbf{1}$ & Kurang & 42 & 56.8 \\
\hline $\mathbf{2}$ & Baik & 32 & 43.2 \\
\hline \multicolumn{2}{l}{ Total } & 74 & 100
\end{tabular}

Data Primer : Oktober 2021

Berdasarkan tabel di atas menunjukan bahwa dari 74 responden tedapat $42(56,8 \%)$ dengan pengetahuan yang kurang. Dan terdapat $32(43,2 \%)$ dengan pengetahuan baik.
Tabel 2

Distribusi Frekuensi berdasarkan Kemandirian Keluarga di Wilayah Kerja Puskesmas Sabulakoa Kabupaten Konawe Selatan

\begin{tabular}{llcc}
\hline No & $\begin{array}{l}\text { Kemandirian } \\
\text { Keluarga }\end{array}$ & Frekuensi & Presentase (\%) \\
\hline $\mathbf{1}$ & Kurang & 44 & 59.5 \\
\hline $\mathbf{2}$ & Baik & 30 & 40.5 \\
\hline \multicolumn{2}{l}{ Total } & 74 & 100
\end{tabular}

Data Primer : Oktober 2021

Dari tabel Distribusi Frekuensi berdasarkan Kemandirian Keluarga menunjukkan bahwa terdapat 44 (59,5\%) responden yang tidak mampu dalam penanganan Stunting

Tabel 3

Distribusi Frekuensi berdasarkan Kejadian Stunting di Wilayah Kerja Puskesmas Sabulakoa Kabupaten Konawe Selatan

\begin{tabular}{llcc}
\hline No & Kejadian Stunting & Frekuensi & Presentase (\%) \\
\hline $\mathbf{1}$ & Normal & 33 & 44.6 \\
\hline $\mathbf{2}$ & Stunting & 41 & 55.4 \\
\hline \multicolumn{2}{l}{ Total } & 74 & 100 \\
\hline \multicolumn{2}{l}{ Data Primer : Oktober 2021 }
\end{tabular}

Dari tabel diatas menunjukkan bahwa dari 74 anak terdapat $41(55,4 \%)$ yang mengalami stunting dan $33(44,6 \%)$ anak dengan status normal di wilayah kerja Puskesmas Sabulakoa Kabupaten Konawe Selatan, Analisis Bivariat 'Pengetahuan' dengan 'Stunting'.

Tabel 4

Hubungan Pengetahuan terhadap Kejadian Stunting di Wilayah Kerja Puskesmas Sabulakoa Kabupaten Konawe Selatan

\begin{tabular}{|c|c|c|c|c|c|c|c|}
\hline \multirow[t]{3}{*}{ Pengetahuan } & \multicolumn{6}{|c|}{ Kejadian Stunting } & \multirow[t]{3}{*}{ P-value } \\
\hline & \multicolumn{2}{|c|}{ Stunting } & \multicolumn{2}{|c|}{ Normal } & \multicolumn{2}{|c|}{ Total } & \\
\hline & $\mathrm{F}$ & $\%$ & $\mathrm{~F}$ & $\%$ & $\mathrm{~F}$ & $\%$ & \\
\hline Kurang & 37 & 88,1 & 5 & 11,9 & 42 & 100 & \\
\hline Baik & 4 & 12,5 & 28 & 87,5 & 32 & 100 & \\
\hline
\end{tabular}


Berdasarkan data diatas proporsi balita stunting lebih banyak pada keluarga dengan Pengetahuan kurang sebanyak 37 orang $(88,1 \%)$ dibandingkan keluarga dengan pengetahuan yang baik sebanyak 4 orang (12,5\%). Berdasarkan uji Chi-square hubungan Pengetahuan terhadap Kejadian Stunting menunjukan nilai signifikan 0,000. Dimana $p$ value $0,000<0,05$ sehingga dapat ditarik kesimpulan yaitu terdapat hubungan antara pengetahuan dan kejadian stunting di wilayah kerja Puskesmas Sabulakoa Kabupaten Konawe Selatan.

\section{KESIMPULAN}

Berdasarkan hasil analisis data dan pembahasan pada penelitian ini maka dapat ditarik kesimpulan yaitu Tingkat Pengetahuan keluarga memiliki hubungan yang signifikan terhadap kejadian stunting dan Kemandirian Keluarga memiliki hubungan yang signifikan terhadap kejadian stunting. Petugas ataupun Staf Kesehatan, Kader serta Pemerintah Kecamatan Sabulakoa lebih aktif lagi dalam penanggulangan Stunting di wilayah Kecamatan Sabulakoa. Diharapkan kepada keluarga balita stunting untuk selalu memperhatikan tumbuh kembang anak dan aktif terhadap kegiatan-kegiatan pencegahan stunting yang dilakukan oleh Staf Puskesmas Sabulakoa maupun Pemerintah Kecamatan Sabulakoas.

\section{REFERENSI}

Danna, M. O. (2019). Hubungan Pengetahuan, Sikap, Dukungan dengan Kemandirian pada Anak Stunting di Puskesmas Bulak Banteng Surabaya.

Dinkes Konawe Selatan. (2018). Profil Dinkes Konawe Selatan.

Elis, A., \& Mustari, R. (2020). The Role of Presenting Exclusive Breastfeeding for The Prevention of Stunting Based on The Culture of Tudang Sipulung. 9(2), 1230-1237.

Handayani, D. (2018). Hubungan Fungsi Afektif Keluarga Dengan Motivasi Diet
Pasien Post Stroke Di Rumah Sakit TK II

Dr. Soepraoen Malang. Universitas Muhammadiyah Malang.

Hasnawati, L, S., \& PAL, J. (2021). Hubungan Pengetahuan Ibu dengan Kejadian Stunting pada Balita Usia 1259 Bulan di Wilayah Kerja Puskesmas Lawawoi Kabupaten Sidrap. Jurnal Pendidikan Keperawatan Dan Kebidanan, 1(1), 7-12.

Herawati, T., Pranaji, D. K., Pujihasvuty, R., \& Latifah, E. W. (2020). Faktor-Faktor yang Memengaruhi Pelaksanaan Fungsi Keluarga di Indonesia. Jurnal Ilmu Keluarga Dan Konsumen, 13(3), 213-227.

Heryanto, H., \& Martha, E. (2019). Kajian

Faktor Penyebab Dan Interveni Gizi Spesifik Untuk Pencegahan Stunting Di Kabupaten Lampung Utara. In Jukema (Jurnal Kesehatan Masyarakat Aceh) (Vol. 5, Issue 2).

Kemenkes RI. (2018). Buletin Jendela Data dan Informasi Kesehatan: Situasi Balita Pendek di Indonesia. Kementerian Kesehatan RI, 20.

Kurniawan, A. (2018). Metodologi Penelitian Pendidikan. Remaja Rosdakarya.

Notoadmojo, S. (2012). Ilmu Perilaku Kesehatan. Rineka Cipta.

Novianti, I., Mardianti, D., \& Muchtar, A. S. (2020). Pemberian ASI dan BBLR Berhubungan dengan Kejadian Stunting pada Balita Usia 12-36 Bulan. Jurnal Kebidanan Malahayati, 6(3).

Nuraeni, R., \& Suharno, S. (2020). Gambaran Faktor-Faktor yang Berhubungan dengan Kejadian Stunting Balita Usia 24-59 Bulan. Syntax Literate; Jurnal Ilmiah Indonesia, 5(10).

Nuraini, \& Martunis, Y. (2017). Komunikasi 4 Tipe Keluarga Terhadap Perilaku Anak Dalam Penyesuaian Sosial. Jurnal Ilmiah Mahasiswa FISIP Unsyiah, 2(4). 